\title{
Biochemical and functional characterization of SpdA, a 2', 3'cyclic nucleotide phosphodiesterase from Sinorhizobium meliloti
}

\author{
Céline Mathieu-Demazière ${ }^{1,2}$, Véréna Poinsot ${ }^{3}$, Catherine Masson-Boivin ${ }^{1,2}$, Anne-Marie Garnerone ${ }^{1,2+}$ \\ and Jacques Batut ${ }^{1,2^{*}+}$
}

\begin{abstract}
Background: 3', 5'CAMP signaling in Sinorhizobium meliloti was recently shown to contribute to the autoregulation of legume infection. In planta, three adenylate cyclases CyaD1, CyaD2 and CyaK, synthesizing 3', 5'cAMP, together

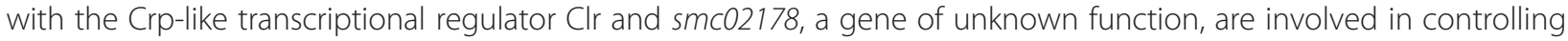
plant infection.

Results: Here we report on the characterization of a gene (smc02179, spdA) at the cyaD1 locus that we predicted to encode a class III cytoplasmic phosphodiesterase.

First, we have shown that spdA had a similar pattern of expression as smc02178 in planta but did not require clr nor 3', 5'cAMP for expression.

Second, biochemical characterization of the purified SpdA protein showed that, contrary to expectation, it had no detectable activity against 3', 5'cAMP and, instead, high activity against the positional isomers 2', 3'cAMP and 2', 3'cGMP. Third, we provide direct experimental evidence that the purified Clr protein was able to bind both 2', 3'cAMP and 3', 5' CAMP in vitro at high concentration. We further showed that Clr is a $3^{\prime}, 5^{\prime} \mathrm{CAMP}$-dependent DNA-binding protein and identified a DNA-binding motif to which Clr binds. In contrast, 2', 3'cAMP was unable to promote Clr specific-binding to DNA and activate smc02178 target gene expression ex planta.

Fourth, we have shown a negative impact of exogenous $2^{\prime}, 3^{\prime} \mathrm{CAMP}$ on $3^{\prime}, 5^{\prime} \mathrm{CAMP}$-mediated signaling in vivo. A spdA null mutant was also partially affected in $3^{\prime}, 5^{\prime}$ cAMP signaling.
\end{abstract}

Conclusions: SpdA is a nodule-expressed 2', 3' specific phosphodiesterase whose biological function remains elusive. Circumstantial evidence suggests that SpdA may contribute insulating 3', 5'cAMP-based signaling from 2', 3' cyclic nucleotides of metabolic origin.

Keywords: Sinorhizobium, 3', 5'cAMP, 2', 3'cAMP, Phosphodiesterase, RNA degradation, Crp

\section{Background}

Sinorhizobium meliloti is a soil-born $\alpha$-proteobacterium that can enter a nitrogen-fixing symbiosis with Medicago sativa (alfalfa) and related legumes. The establishment of the symbiosis relies on a complex molecular dialogue between the two partners that triggers two essential and

\footnotetext{
* Correspondence: Jacques.Batut@toulouse.inra.fr

${ }^{\dagger}$ Equal contributors

'INRA, Laboratoire des Interactions Plantes-Microorganismes (LIPM), UMR441,

F-31326 Castanet-Tolosan, France

${ }^{2}$ CNRS, Laboratoire des Interactions Plantes-Microorganismes (LIPM),

UMR2594, F-31326 Castanet-Tolosan, France

Full list of author information is available at the end of the article
}

overlapping steps, nodulation and infection (see $[1,2]$ for reviews). During the infection process, bacteria colonize root hairs forming Infection Threads (ITs) that extend and proliferate towards the nodule primordium that is formed in the root cortex. Ultimately, rhizobia are released from ITs within nodule cells where they fix molecular dinitrogen. Nodulation and infection are tightly controlled processes and we have shown recently that bacterial adenylate cyclases (ACs) contribute to the negative autoregulation of infection [3].

ACs (EC 4.6.1.1) are enzymes that synthesize cAMP (3', 5' -cyclic adenosine monophosphate) from ATP. There

\section{Biomed Central}


are 6 non-homologous classes of ACs as a typical example of convergent evolution [4,5]. Class III is the universal class whose members can be found in both prokaryotes and eukaryotes although, to our knowledge, their presence in plants has not been established [6]. The number of class III ACs strikingly varies in bacteria. E. coli has none whereas cyanobacteria, mycobacteria and rhizobia, a group of phylogenetically-diverse bacteria [7], have many, up to 32 in the soybean symbiont Bradyrhizobium japonicum. The biological function of class III ACs in bacteria remains poorly understood. Class III ACs synthesize cAMP in response to environmental cues such as light, oxygen, nitrogen and $\mathrm{pH}$ in Cyanobacteria [8] or high osmotic pressure in Myxococcus xanthus $[9,10]$. Class III ACs are also involved in biotic interactions as they contribute to virulence in $M$. tuberculosis, $P$. aeruginosa and in some fungal pathogens [5,11-13]. $\mathrm{CO}_{2}$ and $\mathrm{Ca}^{2+}$ are signals used by pathogens to sense their host environment through their AC-cAMP signaling systems. Candida albicans and mycobacteria express $\mathrm{CO}_{2}$-responsive ACs $[5,14]$ whereas CyaB from $P$. aeruginosa is $\mathrm{Ca}^{2+}$ sensitive. Another example of cAMP-associated signal being used by the human fungal pathogen $C$. albicans to sense the host environment is the bacterial peptidoglycan present in blood serum [15].

We have recently described the first instance of class III ACs contributing to a symbiotic (mutualistic) interaction, between Sinorhizobium meliloti and its host plant Medicago sativa [3]. S. meliloti has 26 class III ACs of overall unknown biological functions with a variety of domain organization [16]. In response to a plant signal present in nodules, three receptor-like adenylate cyclases CyaD1, $\mathrm{CyaD} 2$ and CyaK synthesize the secondary messenger molecule 3', 5'cAMP. 3', 5'cAMP together with the Crp-like transcriptional activator $\mathrm{Cln}$ in turn promote transcription of the target gene smc02178, of unknown biochemical function [3]. We have recently found that this cascade contributes to the autoregulation of the symbiotic interaction. Specifically, activation of the cAMP cascade in nodules inhibits, by a mechanism that remains to be elucidated, secondary infection by rhizospheric bacteria. This control is lost in either a triple cyaD1cyaD2cyaK mutant, a clr or a smc02178 mutant resulting in a hyper-infection phenotype on plants-ie an abundance of abortive ITs on roots-as a consequence of a relaxed control of secondary infection [3].

The concentration of the second messenger 3', 5' cAMP in cells is controlled at the level of its synthesis by ACs and/or by its degradation to 5'AMP by phosphodiesterases (PDEs). PDEs are a superfamily of enzymes divided in three, non-homologous, main classes. All mammalian PDEs as well as several enzymes identified in Drosophila, Caenorhabditis and Saccharomyces cerevisiae belong to class I, whose conserved carboxy-terminal catalytic domain contains two invariant motifs $\mathrm{H}(\mathrm{X}){ }_{3} \mathrm{H}(\mathrm{X})_{25-35} \mathrm{D} / \mathrm{E}$ [17].
Class II PDEs are enzymes from Saccharomyces cerevisiae, Dictyostelium discoideum, Schizosaccharomyces pombe, C. albicans, and Vibrio fischeri [17]. This class of enzymes shares the conserved motif HXHLDH. Class III PDEs belong to the superfamily of metallophosphoesterases [18]. They share the conserved sequence motif $D-(X)_{n^{-}}$ $\mathrm{GD}(\mathrm{X})_{\mathrm{n}}-\mathrm{GNH}[\mathrm{E} / \mathrm{D}]-(\mathrm{X})_{\mathrm{n}}-\mathrm{H}-(\mathrm{X})_{\mathrm{n}}-\mathrm{GHXH}$ as well as a $\beta \alpha \beta \alpha \beta$ secondary structure signature [17].

Here we report on the characterization of a class III PDE from S. meliloti (SpdA, SMc02179) that we anticipated from the localization of the $s p d A$ gene at the $c y a D 1$ locus to be involved in signal termination by turning-over the secondary messenger 3', 5' cAMP. We have found that purified SpdA had actually no detectable activity against $3^{\prime}, 5^{\prime}$ cAMP and, instead, had high activity on the structural isomer 2', 3' cAMP, which may occur in cells as a by-product of RNA degradation [19]. We demonstrated that, contrary to 3', 5' cAMP that promoted $\mathrm{Cl}$ binding to a cognate binding-site, 2', 3'cAMP bound unproductively to Clr. Although SpdA biological function remains to be established, we present circumstantial evidence that SpdA may insulate 3', 5 ' cAMP-mediated signaling from 2', 3' -structural isomers.

\section{Results}

\section{SpdA, a putative PDE}

Inspection of the cyaD1 locus (Figure 1A), that contains the $c l r$ gene as well as the $c l r$-target gene $s m c 02178$, pointed to the $s m c 02179$ gene product as a potential PDE that we subsequently coined SpdA. SpdA belongs to a 15 -member protein family sharing the IPR004843 domain characteristic of a wide range of metallophosphoesterases, among which phosphorine phosphatases, nucleotidases, and class III PDEs. We thus compared SpdA as well as the 14 other IPR004843containing proteins to known PDEs from Mycobacterium tuberculosis (Rv0805), Haemophilus influenzae (Icc) and Escherichia coli (CpdA and CpdB) [20-22].

Overall analysis of the whole protein family indicated no clear phylogenetic relationship between the family members besides the fact that SMc04449 and SMc04018 behaved as an outgroup together with $\mathrm{CpdB}$, a periplasmic 2', 3' cAMP-PDE from E. coli (see Additional file 1). SpdA closest homologue was M. tuberculosis Rv0805 and indeed closer sequence inspection indicated that SpdA contained the 5 sub-domains characteristic of Rv0805 and other class III PDEs [17] (Figure 1B) whereas all other S. meliloti proteins, except SMc02712, had fewer (see Additional file 1). SpdA had a predicted cytoplasmic location and missed the amino-terminal 200-aminoacid membrane anchoring domain of Rv0805 [24].

\section{spdA is expressed in planta, independently of clr and 3',} 5 'cAMP

We probed expression of a translational spdA-lacZ fusion (pGD2179, See Additional file 2) that contained 


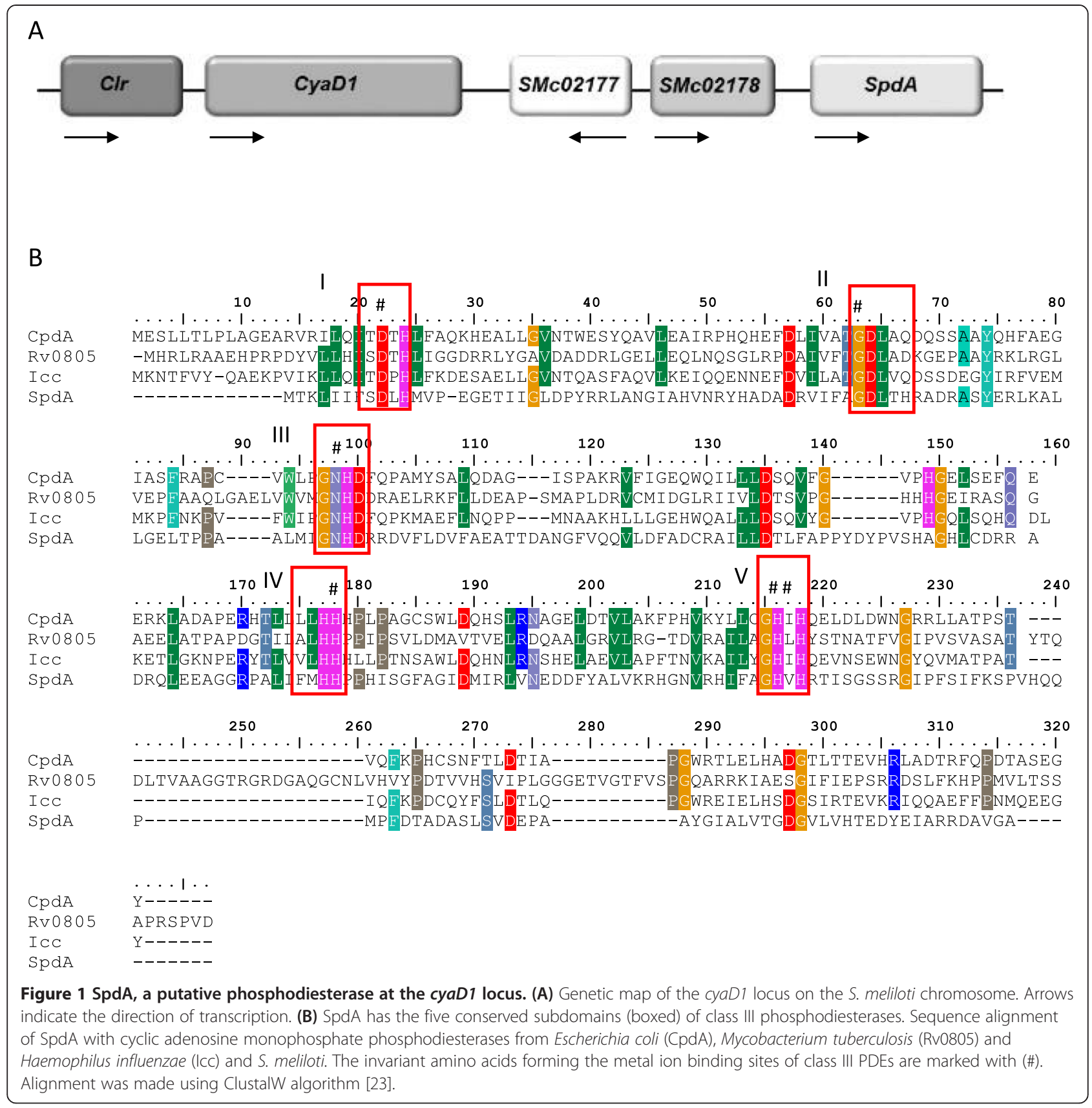

the intergenic region between $s m c 02178$ and $s p d A$ (Figure 1A) as well as the first 12 codons of $s p d A$. The spdA-lacZ fusion did not detectably express ex planta and instead expressed in Medicago sativa nodules with the same pattern as $s m c 02178$ [3] i.e. expression in young nodule primordia and in zones II and III of mature nodules (Figure 2A-F). However, spdA expression in planta was independent of $c l r$, and ex planta expression could not be induced by exogenous $3^{\prime}, 5^{\prime}$ cAMP, in contrast

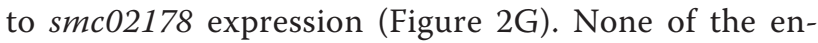
vironmental conditions or compounds which we have tested was able to stimulate spdA expression ex planta, including 3', 5'cGMP, 2' 3 ' 'cAMP, 5' AMP, nodule extracts, root exudates or several growth and stress conditions (See Additional file 3).

Altogether these results indicated that $s p d A$ was expressed in planta from its own promoter and had the same expression pattern as $s m c 02178$ although the two genes were not co-regulated.

\section{SpdA is a 2', 3'cNMP PDE}

We purified the SpdA protein as a carboxy-terminal His $_{6}$ tagged fusion (Figure 3A). Under non-denaturing electrophoretic conditions the protein migrated as a monomer. 

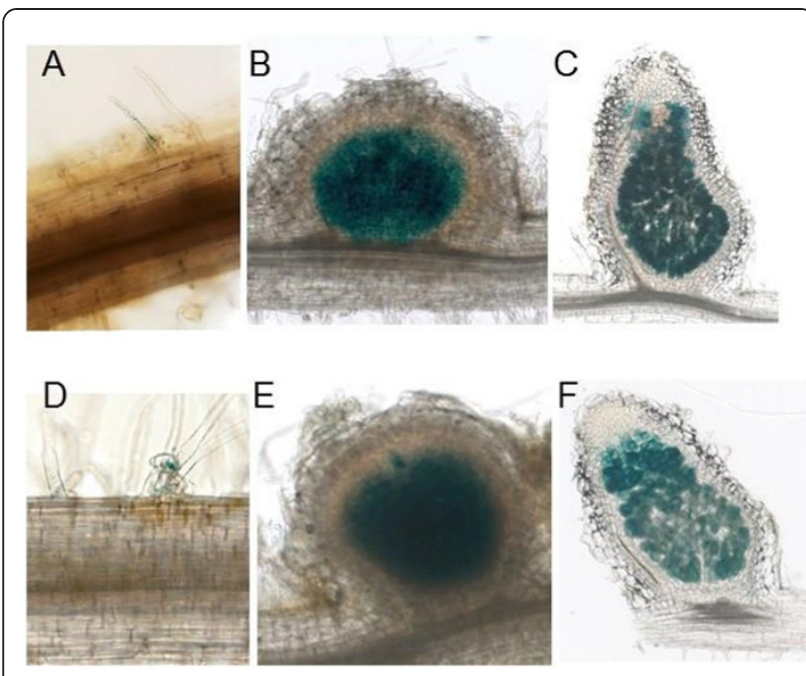

G

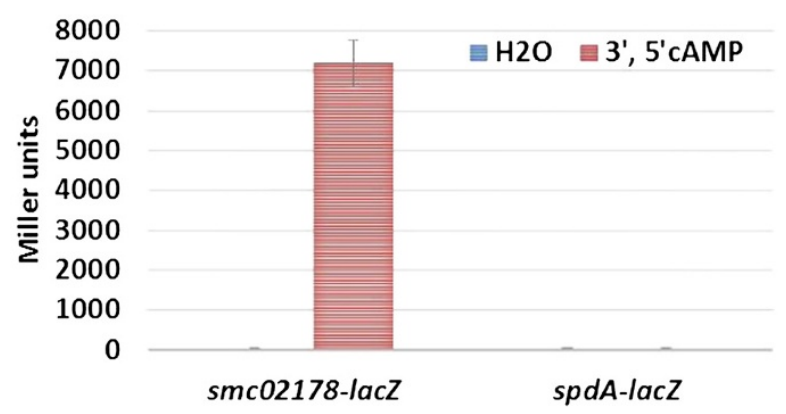

Figure $2 \mathrm{SpdA}$ is expressed in planta, independently of $\mathrm{clr}$. Expression of a spdA-lacZ reporter gene fusion in S. meliloti 1021 [AC] and $c / r$ mutant [D-F], in infection threads (A, D), young nodules (7 dpi) (B, E) and mature nodules (14 dpi) (C, F) of M. sativa. (G) spdA-lacZ expression was monitored ex planta in S. meliloti 1021 strain after addition of $5 \mathrm{mM} \mathrm{3}, 5^{\prime}$ CAMP or water as a negative control. smc02178-lacZ was used as a control.

Purified $\mathrm{His}_{6}-\mathrm{SpdA}$ protein displayed activity against the generic PDE substrate BispNPP in vitro (Figure 3B). SpdA had little or no activity against either $3^{\prime}, 5^{\prime}$ cAMP or $3^{\prime}, 5^{\prime}$ cGMP but significantly hydrolyzed the positional isomers 2', 3'cAMP and 2', 3'cGMP (Figure 3C) which are products of RNA degradation [19]. The $\mathrm{Km}$ for 2', 3' cAMP was $3.7 \mathrm{mM}$ and $\mathrm{kCat}$ was $2 \mathrm{~s}^{-1}$ indicating a slow enzyme with low affinity for its substrate in vitro (See Additional file 4). We observed no inhibition of the enzyme by its substrate and found that $3^{\prime}, 5^{\prime}$ cAMP did not affect SpdA activity on 2', 3'cAMP.

Despite IPR004843-containing proteins being documented metalloenzymes, the metal chelators EDTA, 1-10-Phenanthroline and Bipyridyl, or the addition of $\mathrm{Fe}^{2+}$ or $\mathrm{Mn}^{2+}$ metal ions, had no effect on SpdA activity (see Additional file 5). Mass spectrometry of isolated SpdA confirmed the absence of associated metal including $\mathrm{Mg}^{2+}, \mathrm{Mn}^{2+}$ and $\mathrm{Co}^{2+}$ together with the monomeric state of the protein. Indeed, a well resolved single mass peak corresponding to the monomer was observed after MaxEnt deconvolution of the spectra.

\section{2', 3'cAMP binds unproductively to Clr}

In order to investigate a possible interference of $2^{\prime}, 3^{\prime}$ cyclic nucleotides with $3^{\prime}, 5^{\prime}$ cAMP-signaling we assessed the capacity of 2', 3'cAMP and 3', 5'cAMP to bind Clr in vitro. For this purpose, we purified a GST-tagged version of Clr by affinity purification (Figure 4A). Purified Clr protein was loaded onto a 3', 5' cAMP-agarose column. Bound $\mathrm{Clr}$ protein was then eluted with either the cognate $3^{\prime}, 5^{\prime}$ cAMP nucleotide or its $2^{\prime}, 3^{\prime}$ isomer $(30 \mathrm{mM})$. Both nucleotides displaced agarose-bound $\mathrm{Clr}$ thus suggesting that Clr could bind $3{ }^{\prime}, 5^{\prime} \mathrm{cAMP}$ and $2^{\prime}, 3^{\prime} \mathrm{cAMP}$ at the same binding site (Figure 4B, C).

$\mathrm{Clr}$ is a predicted transcriptional activator of the Crp family [3]. Inspection of the $s m c 02178$ promoter region pointed to a short palindromic sequence (TGTTCCGCGGGAAACA) centered $c a .68$ bp upstream of the predicted start codon that was a potential binding site for Clr. Accordingly, deletion of this motif abolished activation of the $\mathrm{smc} 02178$ promoter by $\mathrm{clr}$ in the presence of exogenously provided 3', 5' cAMP (Figure 5A). In order to directly assess whether this motif was a binding site for the Clr protein, we tested the ability of purified Clr-GST to bind DNA oligomers (28-mers) bracketing the putative Clr-binding motif (Figure 5B) or a mutated version (Figure 5C). We found that $\mathrm{Clr}$ induced a retard in oligomer migration that was strictly dependent on the presence of $3^{\prime}, 5^{\prime}$ cAMP, of an intact Clr-box and was Clr concentrationdependent. However, no clear shifted band was observed, irrespectively of the binding and gel electrophoresis conditions tested, which probably reflected dissociation of the Clr/cAMP/DNA complex. Nevertheless we interpreted this as evidence that Clr bound the predicted Clr-box in a 3', 5'cAMP-dependent manner. 2', 3' cAMP was unable to promote Clr binding to the Clr-box, at the same concentration as 3', 5'cAMP. Mixed incubation of the two nucleotides (1/1) with Clr in vitro showed no detectable effect of 2', 3' 'cAMP on DNA-binding by Clr (Figure 6A, B).

We tested the impact of exogenously provided 2 ', 3' cAMP on smc02178 expression in vivo under different experimental conditions. Exogenous 2', 3'cAMP alone was unable to promote activation of the smc02178-lacZ reporter fusion in vivo, even at high $(7.5 \mathrm{mM})$ concentration (Figure 6C). In contrast 2', 3' cAMP had a negative impact on $3^{\prime}, 5^{\prime}$ ' AMP-driven smc02178 expression. Inhibition reached 50\% (Figure 6C) when $3^{\prime}, 5^{\prime}$ 'cAMP was produced endogenously, as in normal physiological conditions, upon addition to the bacterial culture of a Medicago shoot extract containing the plant signal that triggers activity of the CyaD1CyaD2CyaK ACs [3]. Inhibition was only $30 \%$ when $3^{\prime}, 5^{\prime}$ cAMP was provided exogenously 


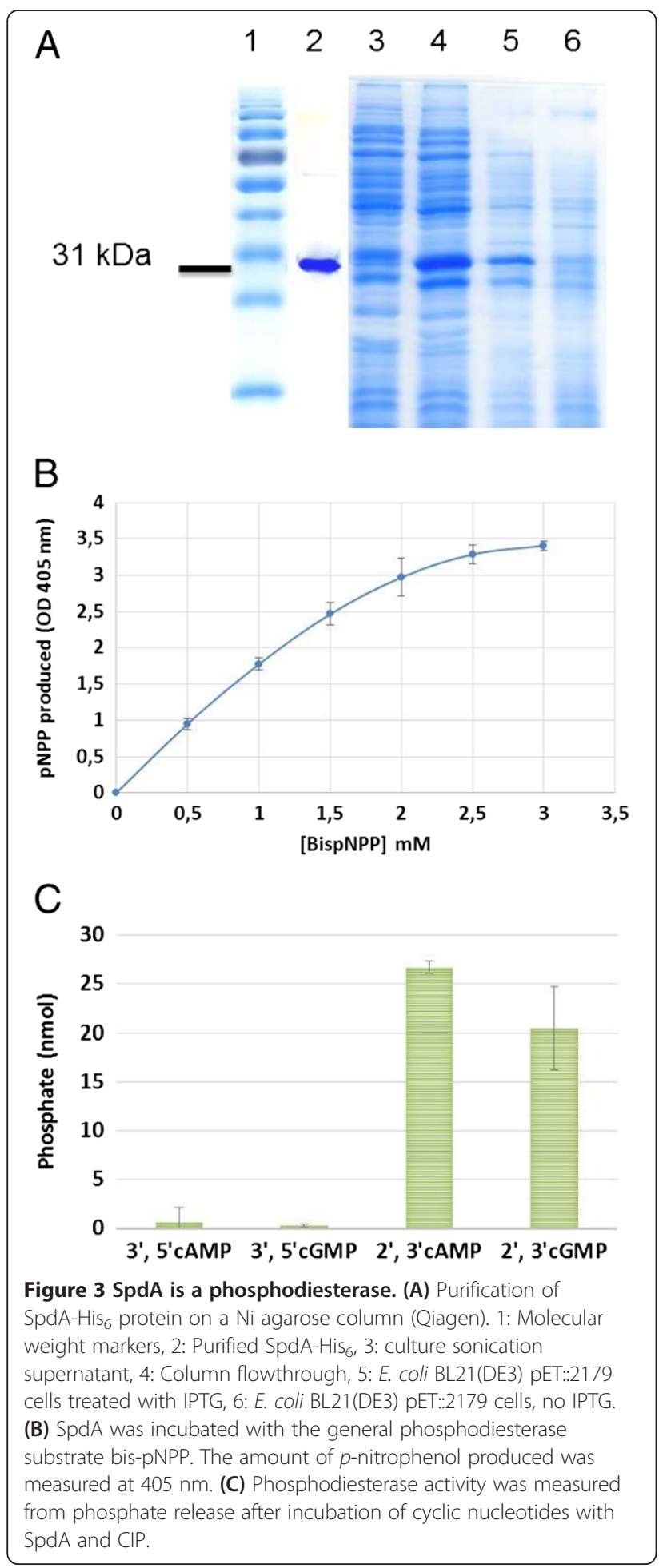

(See Additional file 6). Noteworthy, the negative impact of 2', 3'cAMP was not observed on a constitutive hemA-lacZ reporter fusion (pXLGD4, see Additional file 2 and Additional file 6) suggesting a specific effect of 2', 3' cAMP on 3', 5'cAMP-mediated signaling.
Biological characterization of a S. meliloti spdA null mutant As to get an insight into SpdA biological function we inactivated the corresponding gene by cre-lox deletion [25]. spdA inactivation decreased smc02178-lacZ expression by $c a .25 \%$ in the presence of plant shoot extracts, supposedly by increasing endogenous 2', 3' cNMP concentration in vivo. Combining $s p d A$ inactivation together with exogenous 2', 3'cAMP addition decreased $s m c 02178$ expression to $40 \%$ of wild-type (Figure 6C and See Additional file 6).

The spdA mutant had the same growth characteristics as wild-type both in rich complex medium (LBMC) and in synthetic Vincent medium with mannitol and glutamate (VGM) as carbon and nitrogen sources (see Additional file 7). We observed that exogenous 2', 3'cAMP extended bacterial growth in VGM medium, suggesting that $S$. meliloti can grow by utilizing 2', 3'cAMP, as Yersinia does [26]. However the $\operatorname{spdA}$ mutant did not differ from wild-type in this respect. The $s p d A$ mutant also responded similarly to wild-type to various stress conditions including detergent (SDS) and heat shock (See Additional file 7).

$s p d A$ inactivation had no detectable effect on symbiotic performances, including nodulation, infection and nitrogen fixation (plant dry weight), on Medicago sativa nor on the level or pattern of $s m c 02178$ symbiotic expression in planta (See Additional file 8).

Hence we did not detect any phenotype associated with the $\operatorname{spdA}$ mutation besides its limited effect on 3', 5' cAMP-signaling.

\section{Discussion}

Clr is a $3^{\prime}, 5^{\prime} c N M P-d e p e n d e n t$ DNA-binding transcriptional activator

The findings reported here give experimental support and extend the model proposed by [3], as we demonstrated that $\mathrm{Clr}$ binds to the $s m c 02178$ promoter region at a specific site in a 3', 5'cAMP-dependent manner. The transcription start site (TSS) at the smc02178 promoter was not determined experimentally here. However a single smc02178 TSS was mapped in the closely related strain 2011 by RNA-sequencing of a pool of bacteria living in 16 different free-living and stress conditions [27]. The TSS mapped $61.5 \mathrm{bp}$ downstream of the center of the Clr-box which is the distance typically found in class I $\operatorname{Crp}(\mathrm{CAP})$-dependent promoters. In Class I promoters, a single protein-protein interaction with CAP facilitates the binding of RNA-Polymerase to the promoter to yield the RNA-Polymerase-promoter closed complex [28].

One salient feature of $\mathrm{Clr}$ binding at the smc02178 promoter DNA was instability. In spite of the many binding and electrophoresis conditions tested, we consistently observed a smear instead of a clear-cut band 


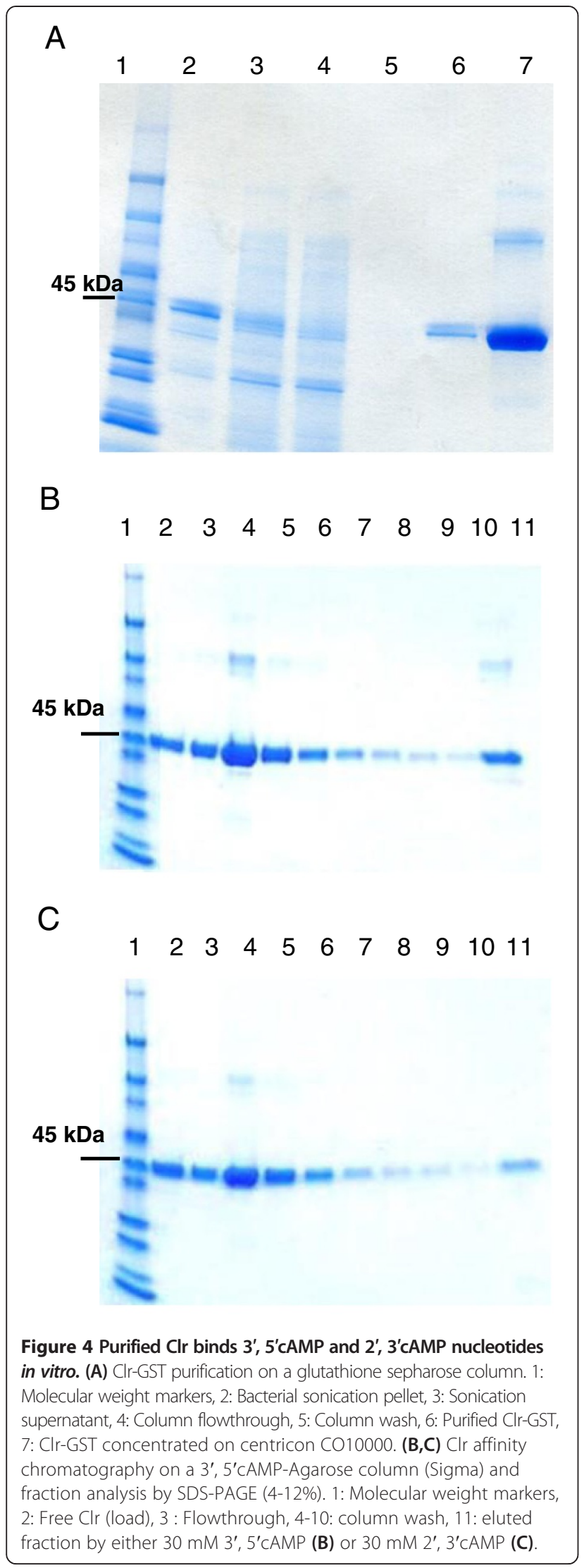

shift upon binding of Clr to its target DNA. One feature that may account for this instability is that the $\mathrm{Clr}$ binding site is TGTTN $_{8} \mathbf{A A C A}$, a shorter palindrome as compared to the consensus $E$. coli $\mathrm{CRP}(\mathrm{CAP})$-binding site TGTGAN ${ }_{6}$ TCACA. Identification of this binding motif, together with transcriptome analysis experiments, will help identification of new Clr targets in the S. meliloti genome.

The reason for which $2^{\prime}, 3^{\prime}$ cAMP did not promote DNA-binding of $\mathrm{Clr}$ is unclear. Although $\mathrm{Clr}$ bound 2', $3^{\prime}$ cAMP in vitro at high concentration $(30 \mathrm{mM})$, it may not do so at the concentration of 2', 3'cAMP that we used in EMSA assays $(200 \mu \mathrm{M})$. Alternatively, 2', 3' ${ }^{\prime}$ AMP may not trigger the appropriate conformational change that allows Crp binding to DNA. Further experiments are needed to distinguish between these two possibilities.

\section{SpdA encodes a 2', 3'cNMP phosphodiesterase}

Class III PDEs are metallophosphoesterases carrying the IPR004843 domain. IPR004843-containing proteins have a wide range of substrates, including cyclic nucleotides, and ensure a variety of biological functions [17]. S. meliloti has 15 uncharacterized IPR004843-containing proteins (see Additional file 1) and we have demonstrated that purified SpdA has a PDE activity in vitro (Figure 3).

We have further found that SpdA had no or little activity against $3^{\prime}, 5^{\prime}$ cAMP or $3^{\prime}, 5^{\prime}$ cGMP and instead had high activity against $2^{\prime}, 3^{\prime}$ cAMP or 2 ', 3 'cGMP. Although this cannot be formally excluded it is unlikely that SpdA would have a predominant $3^{\prime}, 5^{\prime}$ CAMP PDE activity in vivo since a SpdA null mutant had lower, and not enhanced, $s m c 02178$ expression in vivo (Figure 6C).

Substrate specificity varies widely among class III PDEs. CpdA from E. coli and P. aeruginosa, Icc from Haemophilus influenzae are 3', 5'cNMP PDEs [21,22,29] whereas E. coli CpdB was the first described 2', 3'cNMP-specific PDE [30]. Rv0805 from $M$. tuberculosis, although it was first reported as a $3^{\prime}, 5^{\prime}$ cNMP PDE [20], has a much stronger activity (150 times fold) against $2^{\prime}, 3^{\prime}$ cNMP than against $3^{\prime}, 5^{\prime}$ cNMP [31]. Myxococcus xanthus PdeA and PdeB instead hydrolyse $2^{\prime}, 3^{\prime} \mathrm{cNMP}$ and $3^{\prime}, 5^{\prime} \mathrm{cNMP}$ with the same affinity [32]. Hence class III PDEs substrate specificity cannot be predicted from simple primary sequence inspection. It is thus possible that several IPR004843 proteins of S. meliloti display a $2^{\prime}, 3^{\prime}$ cyclic phosphodiesterase activity, thus contributing a functional redundancy.

A surprising feature of SpdA was the absence of associated metal ion which is, to our knowledge, unique among IPR004843-containing proteins. Rv0805 activity for example was not inhibited by metal chelators but was boosted by $\mathrm{Mn}^{2+}$ addition [20]. However, it has been already reported that the iPGM protein from castor bean that belongs to a superfamily of metalloenzymes [33] was actually metal-independent [34]. Moreover, the Carboxy-terminal 


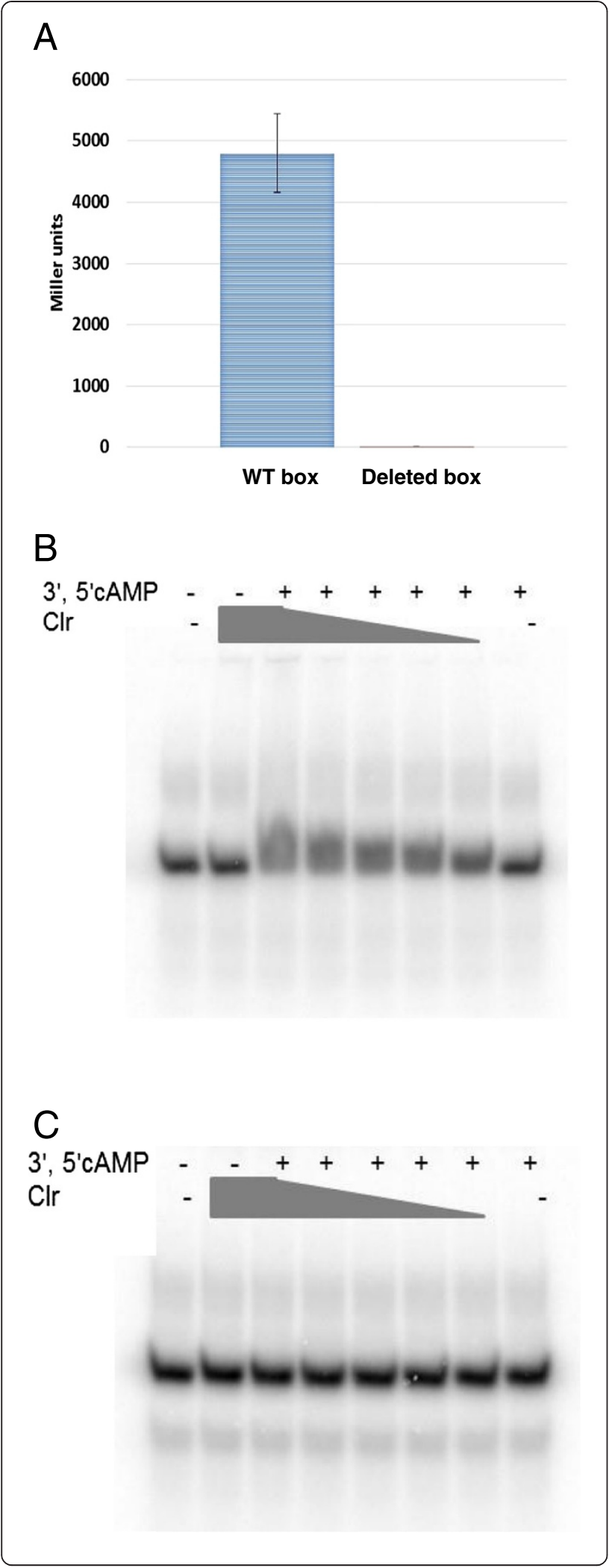

Figure 5 3', 5'cAMP promotes Clr binding to the Clr-box at the smc02178 promoter. (A) smc02178-lacZ expression was monitored ex planta in S. meliloti 1021 WT and a Clr-box deleted strain (TG $\Delta$ CA) after addition of 3', 5'CAMP. (B, C) EMSA assays showing Clr-GST binding to 28-mers oligomers carrying the WT Clr-box (B) or a mutated version (C) (see Additional file 10). Assays were performed in the presence of $1.75 \mathrm{nM}$ oligomers, $200 \mu \mathrm{M}$ 3', 5'CAMP, and varied amounts of $\mathrm{Clr}(35 \mu \mathrm{M}, 17.5 \mu \mathrm{M}, 8.75 \mu \mathrm{M}, 3.5 \mu \mathrm{M}$ and $1.75 \mu \mathrm{M})$. See methods for details.

HD domain of the E. coli tRNA nucleotidyltransferase has a metal-independent phosphodiesterase activity toward 2', 3 'cAMP [35]. Thus, the fact that SpdA displays metalindependent 2', 3' cNMP-phosphodiesterase activity is not completely unprecedented. Mass spectrometric measurements performed under mild ionization conditions also pointed out that the well-defined monomeric form of the protein did not present any demetallation.

The 2', 3'cNMP substrate specificity of SpdA leaves the question of $3{ }^{\prime}, 5^{\prime}$ cAMP turnover intact. One option would be to identify a $3^{\prime}, 5^{\prime} \mathrm{cNMP}$ PDE among the 14 other S. meliloti proteins containing the IPR004843 domain. Another, non-exclusive, possibility would be a regulation of $3^{\prime}, 5$ 'cAMP homeostasis by secretion rather than by degradation [36].

\section{Possible biological functions for SpdA}

Very little is known about the origin, role and fate of 2', 3' cyclic nucleotides. One documented origin is RNA degradation and physiological or stressful conditions may indeed lead 2', 3'cNMPs to accumulate in bacteria. We are not aware of any other origin such as, for example, isomerization of corresponding 3', 5' cyclic nucleotides. In this context, SpdA may serve at least three different, non-exclusive, functions: a metabolic function, a detoxifying function and a role in preventing cross talk with $3^{\prime}, 5^{\prime}$ cAMP signaling.

Although S. meliloti likely metabolized exogenous 2', $3{ }^{\prime}$ cAMP (See Additional file 7), $s p d A$ was not critical for this since the mutant grew indistinctly from wildtype under these conditions.

$2^{\prime}, 3^{\prime}$ cAMP was recently reported to be a toxic compound in kidney cells, that opens mitochondria permeability transition pores thus leading to a pre-apoptotic and necrotic stage [37]. We thus considered whether SpdA may counteract a toxic effect of $2^{\prime}, 3^{\prime}$ cNMPs in $S$. meliloti. However the unaltered growth characteristics of the $s p d A$ mutant as compared to wild-type in various growth (including the presence of exogenous $2^{\prime}, 3^{\prime}$ cAMP) and stress conditions (see Additional file 7) did not give support to this possibility.

A third possibility would be SpdA preventing cross-talk between $2^{\prime}, 3^{\prime}$ cyclic nucleotides and 3', 5'cAMP signaling. Several lines of evidence are in favor of this possibility: (i) the evolutionary-conserved physical location of $s p d A$ 


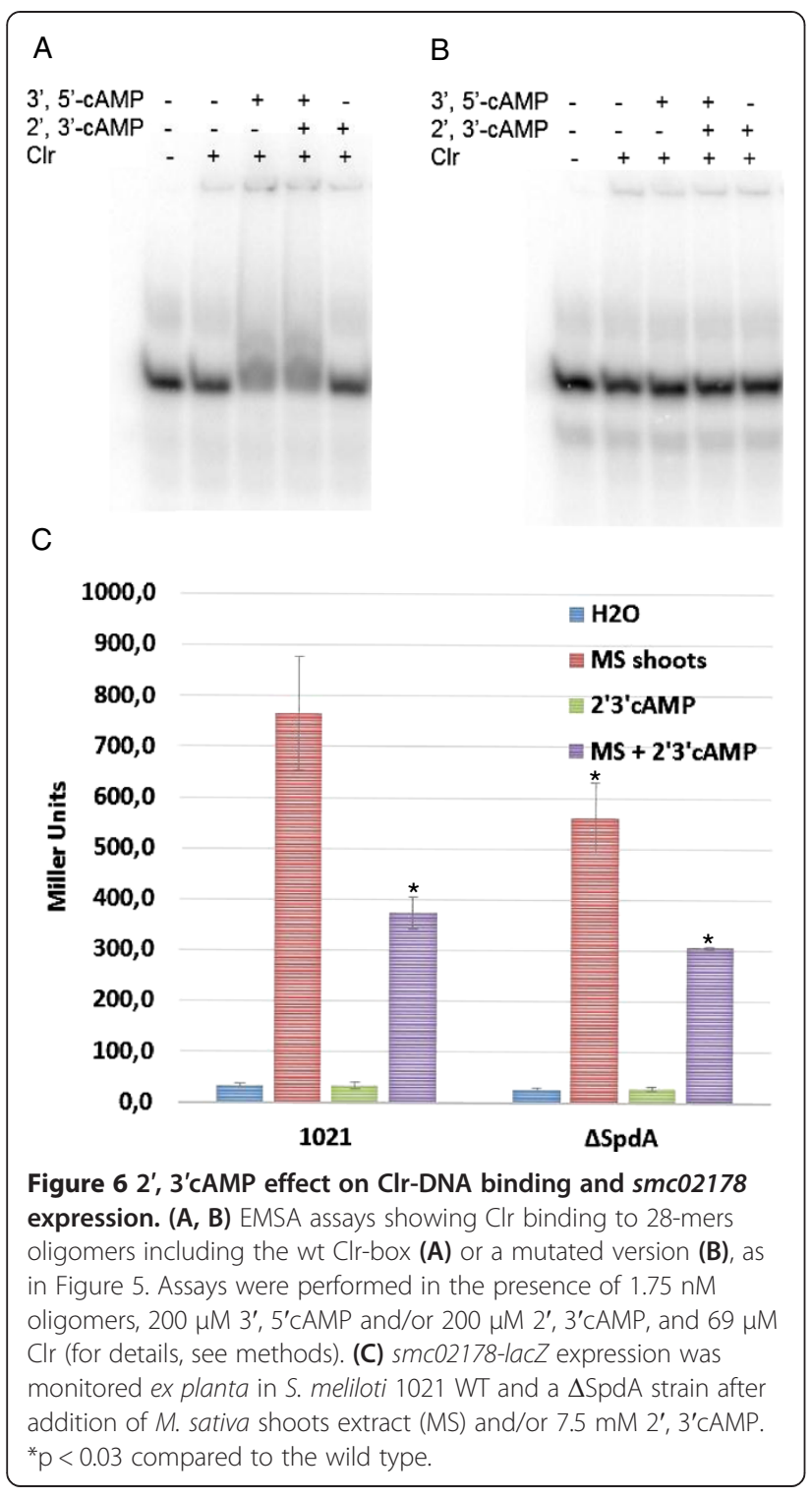

in close proximity to cyaD1, clr and the target gene smc02178 in all the sequenced strains of Sinorhizobium meliloti, Sinorhizobium saheli and Sinorhizobium fredii (https://www.genoscope.cns.fr/agc/microscope/mage/); [38] (ii) $s p d A$ expression in nodules at the same place where $3^{\prime}, 5^{\prime}$ cAMP signaling takes places [3] and where a massive RNA degradation occurs as part of the reorientation of the bacteroid transcriptome to the goal of nitrogen fixation [39] (iii) a significant and specific decrease in $s m c 02178$ expression upon providing exogenous 2 ', 3 ' cAMP (iv) the spurious interaction of $2^{\prime}, 3^{\prime} \mathrm{cAMP}$ with Clr.

Whatever SpdA function, the high $\mathrm{Km}$ value measured in vitro for the $2^{\prime}, 3^{\prime}$ cAMP substrate $(3.7 \mathrm{mM})$ would imply that the cyclic nucleotide accumulates in high amounts in bacteroids, unless specific physiological or biochemical conditions lower Km value in vivo. Developing methods for direct measurements of 2', 3'cNMP levels in bacteroids, where $s p d A$ preferentially expresses, is now needed to clarify this issue. A ribonucleic origin for $2^{\prime}, 3^{\prime}$ cAMP/cGMP would make sense physiologically given the extensive transcriptome reprofiling taking place in bacteroids [39] and the abundance of VapC-type ribonucleases in S. meliloti genome [40]. Intriguingly, the human intracellular pathogen $M$. tuberculosis shares with S. meliloti, despite the large phylogenetic distance separating them, a wealth of ACs, a Clr-like transcriptional regulator as well as a close homolog of SpdA, Rv0805. Rv0805, like SpdA, has a preferential activity-and similar Km value-towards 2', 3 ' cyclic nucleotides [31] and contributes to overall bacterial virulence on macrophages, by a still obscure mechanism $[11,12,24]$. Interestingly, M. tuberculosis and S. meliloti have in commun a high number of VapC-type RNases of the $\operatorname{VapC}(B)$-toxin (antitoxin) family [40,41]. Altogether this suggests the intriguing possibility that SpdA, Rv0805 and other cytoplasmic PDEs may constitute a physiological adaptation in bacteria with a high RNA turnover, possibly in relationship with $3^{\prime}, 5^{\prime}$ cAMPmediated signaling.

\section{Conclusion}

Signal transduction in bacteria is dominated by twocomponent regulatory systems [42]. However, some bacteria, including important pathogens and symbionts, use cyclic or dicyclic nucleotide signaling for modulating interaction with their abiotic or biotic environment $[43,44]$. Characterization of enzymes and mechanisms that synthesize and degrade secondary messenger molecules, restrict their diffusion within the cell and prevent cross-talking by diffusible isomers, is needed for fully understanding cyclic nucleotide signaling. In the context of characterizing $3^{\prime}, 5^{\prime}$ cAMP-mediated signaling in the S. meliloti-Medicago symbiosis, we have identified a plantexpressed 2', 3'cAMP/cGMP specific phosphodiesterase whose biological function remains to be elucidated. Circumstantial evidence suggests that one SpdA function could be to insulate $3^{\prime}, 5^{\prime}$ cAMP-based signaling from 2', 3' cyclic nucleotides of metabolic origin.

\section{Methods}

\section{Bacterial strains, plasmids, and growth conditions}

Plasmids and bacterial strains used in this study are listed in Additional file 2 and Additional file 9 respectively. S. meliloti strains were grown at $28^{\circ} \mathrm{C}$ in rich $\mathrm{LB}$ medium supplemented with $2.5 \mathrm{mM} \mathrm{CaCl} 2$ and $2.5 \mathrm{mM} \mathrm{MgSO}_{4}$ (LBMC) or in modified Vincent synthetic medium with glutamate $(0.1 \%)$ and mannitol (1\%) as nitrogen and carbon sources, respectively (VGM) [45]. E. coli strains were grown at $37^{\circ} \mathrm{C}$ in rich $\mathrm{LB}$ medium.

The concentrations of antibiotics used for S. meliloti cultures were $200 \mu \mathrm{g} / \mathrm{ml}$ for streptomycin, $100 \mu \mathrm{g} / \mathrm{ml}$ for 
neomycin, $10 \mu \mathrm{g} / \mathrm{ml}$ for tetracycline, and $30 \mu \mathrm{g} / \mathrm{ml}$ for gentamicin. The concentrations of antibiotic used for E. coli cultures were $50 \mu \mathrm{g} / \mathrm{ml}$ for ampicillin and $25 \mu \mathrm{g} / \mathrm{ml}$ for kanamycin.

\section{Stress responses}

Bacterial response to SDS and heat shock was evaluated by analysis of the growth curves of WT and $\triangle \mathrm{SpdA}$ mutant in liquid LBMC. Strains were challenged with SDS $(0.01 \% \mathrm{v} / \mathrm{v})$ at $\mathrm{OD}_{600} 0.1$ and heat shock $\left(50^{\circ} \mathrm{C}\right.$ for $\left.20 \mathrm{~min}\right)$ was applied to overnight cultures before dilution at $\mathrm{OD}_{600}$ 0.1. Aliquots were collected at different time intervals, $\mathrm{OD}_{600}$ was measured and residual growth was determined [46].

\section{Construction of plasmids and mutant strains}

Primers used for DNA amplification are listed in Additional file 10. S. meliloti 1021 was used as template for DNA amplification. For deletion of the $\operatorname{spdA}$ gene, we used the cre-lox system [25]. PCR fragments encompassing the upstream/amino-terminal coding region and the downstream/carboxyl-terminal coding region of $s p d A$ were amplified using CreLox 2179 up Left-CreLox 2179 up Right and 2179 Down Ncol-2179 Down HincII as primers (See Additional file 10), digested by SacI-SacII and NcoI-HincII, and cloned into the SacI-SacII and NcoIHincII restriction sites of pCM351, respectively. The resulting plasmid was introduced into the $S$. meliloti 1021 strain by conjugation. Transconjugants sensitive to tetracycline and resistant to gentamicin were screened. A $\triangle s p d A$ mutant was selected. The $s p d A$-expressing construct pET::2179 was obtained after amplification of the $s p d A$ gene-coding region using S. meliloti 1021 genomic DNA as template and LNdeI2179 and RHindIII 2179 as primers. The PCR fragment was digested with NdeI and HindIII and cloned into the NdeI-HindIII digested pET-22b plasmid to yield pET::2179. The Clr-expressing construct pGEX::clr was obtained after amplification of the clr gene-coding region using S. meliloti 1021 genomic DNA as template and ClrBamHI and ClrEcoRI as primers. The PCR fragment was digested with BamHI and EcoRI and cloned into the BamHI-EcoRI digested pGEX-2T to yield pGEX::clr.

To construct pGD2179, that carries a spdA-lacZ translational fusion, a 177-bp PCR fragment encompassing the $s p d A$ promoter region was amplified using 2179left and 2179right primers, digested with HindIII and BamHI, and cloned in the in-frame orientation at the same sites of the lac $Z$ translational fusion plasmid pGD926. The pAMG2178 plasmid was obtained after amplification of the $s m c 02178$ promoter-coding region using $S$. meliloti 1021 genomic DNA as template and BamHI 2178 and Hind BoxL as primers. For pAMG2178 $\Delta$ Clrbox, PCR fragments encompassing the upstream region $\mathrm{Clr}$ box and the downstream

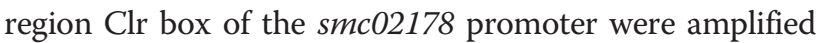
using $2178 \mathrm{H}$-BoxLPstI and X 2178-BoxRPstI as primers. The two fragments obtained were digested by PstI and then ligated and amplified by PCR using BamHI 2178 and Hind BoxL as primers. The two fragments p $2178 \mathrm{WT}$ (134 bp) and p2178 $\Delta$ Clrbox (128 bp) were then cloned into pGD926 vector.

All constructs were verified by PCR and Sanger sequencing in $E$. coli and by PCR in S. meliloti. Plasmids were transferred from $E$. coli to $S$. meliloti by triparental mating using pRK600 as the helper plasmid. pET::2179 and pGEX::clr were directly transferred into E. coli BL21(DE3) and SP850 respectively.

\section{Protein purifications}

For $\mathrm{His}_{6}$-SpdA purification, an overnight culture of $E$. coli strain BL21(DE3) pET::2179 expressing wild-type S. meliloti $s p d A$ was diluted at $\mathrm{OD}_{600} 0.1$ in $250 \mathrm{ml}$ of $\mathrm{LB}$ medium containing Ampicillin (Amp $50 \mu \mathrm{g} / \mathrm{ml}$ ). Cultures were grown with shaking at $28^{\circ} \mathrm{C}$. When the $\mathrm{OD}_{600}$ reached 0.8, $1 \mathrm{mM}$ isopropyl $\beta$-D-1-thiogalactopyranoside (IPTG) was added, and cultures were grown for 5 additional hours. Bacteria were collected by centrifugation $(10,000 \mathrm{x} g$ for $30 \mathrm{~min}$ at $4^{\circ} \mathrm{C}$ ), and pellets were washed with $60 \mathrm{ml}$ Tris buffer (20 mM Tris- $\mathrm{HCl}$ [pH 8.0]). Bacteria were collected by centrifugation $\left(10,000 \mathrm{x}\right.$ for $30 \mathrm{~min}$ at $\left.4^{\circ} \mathrm{C}\right)$, and pellets were stored at $-80^{\circ} \mathrm{C}$. All of the subsequent procedures were performed at $4^{\circ} \mathrm{C}$. Thawed bacteria were resuspended in $5 \mathrm{ml}$ of buffer A (50 mM Tris- $\mathrm{HCl}$ [pH 8.0], $250 \mathrm{mM}$ $\mathrm{NaCl}, 10 \%$ glycerol) and lysed by sonication. The lysates were centrifuged to remove the cell debris at 10,000x $\mathrm{g}$ for $30 \mathrm{~min}$ at $4^{\circ} \mathrm{C}$. The supernatant was loaded to a Ni-NTA resin (Qiagen) equilibrated with buffer B $(50 \mathrm{mM}$ Tris- $\mathrm{HCl}$ [pH 8.0], $250 \mathrm{mM} \mathrm{NaCl}, 10 \%$ glycerol, $10 \mathrm{mM}$ Imidazol, and $5 \mathrm{mM} \beta$-Mercaptoethanol). After washing with the buffer B containing $20 \mathrm{mM}$ Imidazol, the bound protein was eluted using the buffer B containing $250 \mathrm{mM}$ Imidazol. Protein was desalted into buffer A. Purified protein aliquots were stored at $-80^{\circ} \mathrm{C}$.

For Clr-GST purification, an overnight culture of $E$. coli strain SP850 pGEX::clr expressing wild-type S. meliloti clr was diluted at $\mathrm{OD}_{600} 0.1$ in $1 \mathrm{l}$ of LB medium containing Ampicillin (Amp $50 \mu \mathrm{g} / \mathrm{ml}$ ) and Kanamycin (Kan $25 \mu \mathrm{g} / \mathrm{ml}$ ). Cultures were grown with shaking at $28^{\circ} \mathrm{C}$. When the $\mathrm{OD}_{600}$ reached $0.8,1 \mathrm{mM}$ isopropyl $\beta$-D-1-thiogalactopyranoside (IPTG) was added, and cultures were grown for 5 additional hours. Bacteria were collected by centrifugation $\left(10,000 \mathrm{x} \mathrm{g}\right.$ for $30 \mathrm{~min}$ at $\left.4^{\circ} \mathrm{C}\right)$, and pellets were washed with $60 \mathrm{ml}$ PBS buffer $(140 \mathrm{mM} \mathrm{NaCl}, 2.7 \mathrm{mM} \mathrm{KCl}, 10 \mathrm{mM}$ $\left.\mathrm{Na}_{2} \mathrm{HPO}_{4}, 1.8 \mathrm{mM} \mathrm{KH} \mathrm{PO}_{4},[\mathrm{pH} 7.3]\right)$. Bacteria were collected by centrifugation $\left(10,000 \mathrm{x}\right.$ g for $30 \mathrm{~min}$ at $\left.4^{\circ} \mathrm{C}\right)$, and pellets were stored at $-80^{\circ} \mathrm{C}$. All of the subsequent procedures were performed at $4^{\circ} \mathrm{C}$. Thawed bacteria were resuspended in $10 \mathrm{ml}$ PBS buffer and lysed by sonication. 
The lysates were centrifuged to remove the cell debris at $10,000 \mathrm{x} g$ for $30 \mathrm{~min}$ at $4^{\circ} \mathrm{C}$. The supernatant was loaded to a Glutathione sepharose 4B resin (GE Healthcare) equilibrated with PBS buffer. After washing with PBS buffer, the bound protein was eluted using $50 \mathrm{mM}$ Tris- $\mathrm{HCl}$ buffer [pH 8.0] containing $10 \mathrm{mM}$ reduced glutathione. Protein was desalted on Amicon CO 10,000 (Millipore) and buffer exchanged with $0.1 \mathrm{M}$ Phosphate buffer [pH 7.0] containing $50 \mathrm{mM} \mathrm{NaCl}$. Purified protein aliquots containing 10\% glycerol were stored at $-80^{\circ} \mathrm{C}$.

\section{Infusion ESI-Q-TOF experiment}

ElectroSpray Ionization coupled with a quadrupole-time of flight tandem was used in the positive ion mode using a Q-TOF Ultima Instrument (Waters). The SpdA protein was dissolved in water with $0.05 \%$ formic acid and directly introduced into the source at a flow rate of $5 \mu \mathrm{l} / \mathrm{min}$. Capillary entrance voltage was set to $2.7 \mathrm{kV}$, and dry gas temperature to $150^{\circ} \mathrm{C}$. Voltages: Cone: $80 \mathrm{~V}$, Rf lens: $40 \mathrm{~V}$. MS profile [500 (10\%), 1500 (60\%), 2500 (20\%), ramp 10\%]. Scanning domain: $\mathrm{m} / \mathrm{z}$ 1000-3000. Calibration was performed with orthophosphoric clusters. Continuum spectra exhibiting multicharged ions were transformed into molecular mass envelops using the MaxEnt 1 software.

\section{Electromobility shift assay}

A set of DNA probes covering the predicted Clr binding palindrome were obtained by annealing two complementary oligonucleotides. The annealing reactions were performed in water with $25 \mu \mathrm{M}$ strand + (WTN8+ or MN8+ (see Additional file 10)) and $25 \mu \mathrm{M}$ strand-(WTN8-or MN8-(see Additional file 10)) for each probe in a total reaction volume of $100 \mu \mathrm{l}$. Mixes were incubated at $95^{\circ} \mathrm{C}$ during 5 min following by slow cooling to $25^{\circ} \mathrm{C}$. $175 \mathrm{nM}$ double-strands probes were end labelled using $20 \mu \mathrm{Ci}$ of $\left[\mathrm{ATP}_{-}-{ }^{32} \mathrm{P}\right]$ and $10 \mathrm{U}$ of $\mathrm{T} 4$ polynucleotide kinase (Promega). Probes (1.75 nM each) were incubated in binding buffer (10 mM Tris [pH 8.0], 1 mM EDTA, $1 \mathrm{mM}$ DTT, $10 \mu \mathrm{g} / \mathrm{ml}$ bovine serum albumin, $100 \mathrm{mM} \mathrm{KCl}$ ) containing $50 \mu \mathrm{g} / \mathrm{ml}$ poly $(2$ '-deoxyinosinic-2' -deoxycytidylic acid) (Sigma) and $10 \%$ glycerol for $30 \mathrm{~min}$ at room temperature with purified $\mathrm{Clr}$ and $3^{\prime}, 5^{\prime} \mathrm{cAMP}$ or $2^{\prime}$, 3 'cAMP added to the concentrations indicated in the figure legends in a final reaction volume of $15 \mu \mathrm{l}$. Samples were subjected to electrophoresis on a $10 \%$ polyacrylamide TBE $0.5 \mathrm{X}$ gel containing 4\% PEG-8000. Electrophoresis was conducted in TBE $0.5 \mathrm{X}$ buffer at $80 \mathrm{~V}$ at room temperature. Gels were dried and analysed by autoradiography.

\section{Plant assays and plant extracts preparation}

Seeds of $M$. sativa cv. Europe were surface sterilized, germinated, and allowed to grow in $12-\mathrm{cm}^{2}$ plates containing slanting nitrogen-free Fahraeus agar medium for 3 days at $22^{\circ} \mathrm{C}$ with day/night cycles of $16 / 8 \mathrm{~h}$. The plants were inoculated with $2.10^{3}$ bacteria per plant. Nodules were counted every day during 8 days then every 2 days until 35 days post-inoculation (dpi). At $35 \mathrm{dpi}$, shoots were collected and dried overnight at $65^{\circ} \mathrm{C}$ for weight measurements. Plant extracts were prepared as previously described [3].

\section{$\beta$-Galactosidase assays}

S. meliloti strains carrying the pGD2178, pXLGD4 or pGD2179 plasmids were grown at $28^{\circ} \mathrm{C}$ in VGM. Overnight cultures were diluted to an $\mathrm{OD}_{600}$ of 0.1 in VGM and grown for an additional $2 \mathrm{~h}$. 5 ml-cultures supplemented with $3^{\prime}, 5^{\prime}$ cAMP $(2.5 \mathrm{mM}$ or $5 \mathrm{mM}), 2^{\prime}, 3^{\prime}$

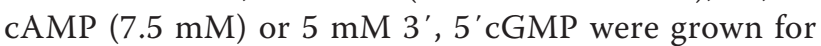
an additional 5 hours at $28^{\circ} \mathrm{C}$. Overnight incubation was used for other potential inducers listed in Additional file 3. $\beta$-Galactosidase activities were measured (Miller units) using $1 \mathrm{ml}$ of culture (or $0.1 \mathrm{ml}$ for overnight cultures), as previously described [47].

\section{Cytological techniques}

Plants were inoculated with S. meliloti strains carrying the pGD2178 or the pGD2179 plasmid. Entire roots were collected $7 \mathrm{dpi}$ or $14 \mathrm{dpi}$, fixed with $2 \%$ (vol/vol) glutaraldehyde solution for $1.5 \mathrm{~h}$ under vacuum, rinsed three times in $\mathrm{Z}$ buffer (0.1 M potassium phosphate buffer [ $\mathrm{pH} 7.4$ ], $1 \mathrm{mM} \mathrm{MgSO}_{4}$, and $10 \mathrm{mM} \mathrm{KCl}$ ), and stained overnight at $28^{\circ} \mathrm{C}$ in $\mathrm{Z}$ buffer containing $0.08 \%$ 5-bromo-4-chloro-3indolyl-D-galactoside (X-gal), $5 \mathrm{mM} \mathrm{K}_{3} \mathrm{Fe}(\mathrm{CN})_{6}$, and $5 \mathrm{mM}$ $\mathrm{K}_{4} \mathrm{Fe}(\mathrm{CN})_{6}$. Nodules were harvested at $14 \mathrm{dpi}$, fixed with $2 \%(\mathrm{v} / \mathrm{v})$ glutaraldehyde in $\mathrm{Z}$ buffer, and then sliced into $70 \mu \mathrm{m}$-thick longitudinal sections using a vibrating-blade microtome (VT1000S; Leica) before staining overnight at $28^{\circ} \mathrm{C}$. Entire roots or nodule sections were observed under a light microscope.

\section{Phosphodiesterase activity assays}

Biochemical assays were performed in $50 \mathrm{mM}$ Tris- $\mathrm{HCl}$ [pH 8], $5 \mathrm{mM} \beta$-Mercaptoethanol, $10 \mathrm{mM} \mathrm{NaCl}, 100 \mu \mathrm{M}$ $\mathrm{MnCl}_{2}$, and 0 to $2.5 \mathrm{mM}$ bis- $P$-nitrophenyl phosphate in a total volume of $50 \mu \mathrm{l}$. Reactions were initiated by the addition of $120 \mathrm{nM}$ SpdA and the reaction was stopped after $10 \mathrm{~min}$ at $25^{\circ} \mathrm{C}$ by the addition of $10 \mu \mathrm{l}$ of $200 \mathrm{mM} \mathrm{NaOH}$. Release of $p$-nitrophenol was determined by measuring the absorbance at $405 \mathrm{~nm}$. Cyclic NMP assays were performed in reaction mixtures containing $50 \mathrm{mM}$ Tris- $\mathrm{HCl}[\mathrm{pH} 8]$, $5 \mathrm{mM} \beta$-Mercaptoethanol, $10 \mathrm{mM} \mathrm{NaCl}, 10 \mathrm{mM}$ cyclic nucleotides, $1 \mu \mathrm{M}$ SpdA and $10 \mathrm{U}$ calf intestine phosphatase (CIP) were incubated $10 \mathrm{~min}$ at $25^{\circ} \mathrm{C}$, and were stopped by the addition of $1 \mathrm{ml}$ Biomol Green Reagent (Enzo). Released of phosphate was determined by measuring the absorbance at $620 \mathrm{~nm}$. The kinetic values were determined using the equation of $v=V_{\max }[\mathrm{S}] /\left(K_{\mathrm{m}}+[\mathrm{S}]\right)$ where $v, V_{\max }$, 
$K_{\mathrm{m}}$ and [S] represent the initial velocity, the maximum velocity, the Michaelis constant and the substrate concentration, respectively. The $K_{\text {cat }}$ was calculated by dividing $V_{\max }$ by the concentration of enzyme used in the reaction $\left(K_{\text {cat }}=V_{\text {max }} /[\right.$ enzyme $\left.]\right)$.

\section{cAMP-binding assay}

3', 5'cAMP affinity matrix was purchased from Sigma. $4.5 \mathrm{mM}$ of purified Clr-GST was incubated in batch with $200 \mu \mathrm{l}$ of $3{ }^{\prime}, 5^{\prime}$ cAMP-agarose, previously equilibrated in buffer A (100 mM sodium phosphate buffer [pH 7], $50 \mathrm{mM} \mathrm{NaCl}$, at $4^{\circ} \mathrm{C}$ during 30 min on a rotary mixer. After washing 7 times with $1 \mathrm{ml}$ buffer $\mathrm{A}$, bound protein was eluted by 30 min incubation in $1 \mathrm{ml}$ buffer A supplemented with $30 \mathrm{mM} \mathrm{3}, 5^{\prime} \mathrm{CAMP}$ or $30 \mathrm{mM} \mathrm{2} 2^{\prime}, 3^{\prime} \mathrm{CAMP}$ at $4^{\circ} \mathrm{C}$. Fractions were analysed by $12 \%$ SDS-PAGE.

\section{Additional files}

Additional file 1: SpdA, a putative Class III phosphodiesterase. (A) Phylogenetic tree generated with Phylogeny.fr [1]. The tree shows the phylogenetic relationship of the 15 IPR004843-containing proteins of S. meliloti with known phosphodiesterases from M. tuberculosis (Rv0805), H. influenzae (Icc) and E. coli (CpdA and CpdB). (B) Table showing the distribution of the five class III PDE subdomains among the 15 IPR004843-containing proteins from S. meliloti.

Additional file 2: Plasmids used in this study.

Additional file 3: Molecules and conditions tested for expression of spdA ex planta.

Additional file 4: Enzymatic characteristics of purified SpdA

(A)Lineweaver-Burk representation of SpdA kinetics of hydrolysis of 2', 3' cAMP. Purified SpdA was assayed as described in methods. (B)SpdA kinetic values.

Additional file 5: SpdA does not require metal cofactor for 2', 3' cAMP hydrolysis. (A) Activity assayed in absence (CT) or presence of ions chelators. (B) SpdA activity in absence (CT) or presence of added bivalent ions.

Additional file 6: 2', 3' cAMP weakens smc02178-lacZ expression. (A) smc02178-lacZ expression was monitored ex planta in S.meliloti 102

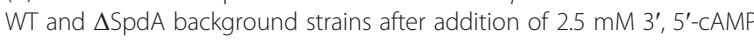

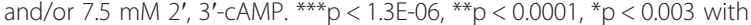
respect to the wild type. (B) hemA-lacZ expression was monitored ex planta in S. meliloti $1021 \mathrm{WT}$ and $\triangle$ SpdA background strains after addition of $2.5 \mathrm{mM} \mathrm{3',} \mathrm{5'-CAMP} \mathrm{and/or} 7.5 \mathrm{mM}$ 2', 3'-CAMP.

Additional file 7: Growth characteristics and stress adaptability of the $\Delta$ SpdA mutant. (A) Growth curves of 1021 WT and $\Delta$ SpdA mutant strains in LBMC or in VGM supplemented or not with $7.5 \mathrm{mM} \mathrm{2',} \mathrm{3'} \mathrm{CAMP.}$ ( $B$ and $C$ ) sensitivity of $1021 \mathrm{WT}$ and $\triangle$ SpdA strains to SDS (B) and heat shock (C) (see methods for details).

Additional file 8: spdA mutant symbiotic phenotype. (A) Nodulation kinetics on M. sativa following inoculation with S. meliloti 1021 and $\triangle$ SpdA mutant. (B) Dry weight of $M$. sativa shoots $35 \mathrm{dpi}(C$ and $D$ ). Expression pattern of the smc02178-lacZ reporter gene fusion in young (7dpi) nodules of M. sativa following inoculation with S. meliloti 1021 (C) and $\triangle$ SpdA mutant (D)

Additional file 9: Bacterial strains used in this study.

Additional file 10: Primers and oligonucleotides used in this work.

\section{Competing interests}

The authors declared they have no competing interests.
Authors' contributions

$C M D, V P$ and $A M G$ collected and analysed data. AMG and JB directed the work. JB and CMB wrote and revised the manuscript. All authors have read and approved the final version of this manuscript.

\section{Acknowledgements}

We thank the Florimond-Desprez company (Cappelle en Perche, France) for generous gift of Medicago seeds. CMD was supported by a PhD fellowship from the French Ministère de l'Enseignement supérieur et de la Recherche. We thank Chang-Fu Tian (LIPM, State Key Laboratory of Agrobiotechnology, China Agricultural University) for his contribution to the early stages of this study and Ludovic Cottret (Plateforme Bioinformatique LIPM-SPE) for his help with phylogenetic analyses.

This work was funded in part by the ANR "RhizocAMP" (ANR-10-BLAN-1719) and the Pôle de Compétitivité "Agrimip Innovation Sud Ouest". This work is part of the "Laboratoire d'Excellence" (LABEX) entitled TULIP (ANR-10-LABX-41)

\section{Author details}

${ }^{1}$ INRA, Laboratoire des Interactions Plantes-Microorganismes (LIPM), UMR441, F-31326 Castanet-Tolosan, France. ${ }^{2}$ CNRS, Laboratoire des Interactions Plantes-Microorganismes (LIPM), UMR2594, F-31326 Castanet-Tolosan, France. ${ }^{3}$ Laboratoire IMRCP UMR UPS/CNRS 5623, Université Paul Sabatier, Toulouse Cedex 31062, France.

Received: 25 July 2013 Accepted: 11 November 2013

Published: 26 November 2013

\section{References}

1. Jones KM, Kobayashi H, Davies BW, Taga ME, Walker GC: How rhizobial symbionts invade plants: the Sinorhizobium-Medicago model. Nat Rev Microbiol 2007, 5(8):619-633.

2. Murray JD: Invasion by invitation: rhizobial infection in legumes. Mol Plant Microbe Interact 2011, 24(6):631-639.

3. Tian CF, Garnerone AM, Mathieu-Demazière C, Masson-Boivin C, Batut J: Plant-activated bacterial receptor adenylate cyclases modulate epidermal infection in the Sinorhizobium meliloti-Medicago symbiosis. Proc Natl Acad Sci USA 2012, 109(17):6751-6756.

4. He Y, Li N, Chen Y, Chen X, Bai J, Wu J, Xie J, Ying H: Cloning, expression, and characterization of an adenylate cyclase from Arthrobacter sp. CGMCC 3584. Appl Microbiol Biotechnol 2012, 96(4):963-970.

5. McDonough KA, Rodriguez A: The myriad roles of cyclic AMP in microbial pathogens: from signal to sword. Nat Rev Microbiol 2012, 10(1):27-38

6. Linder JU: Class III adenylyl cyclases: molecular mechanisms of catalysis and regulation. Cell Mol Life Sci 2006, 63(15):1736-1751.

7. Masson-Boivin C, Giraud E, Perret X, Batut J: Establishing nitrogen-fixing symbiosis with legumes: how many rhizobium recipes? Trends Microbiol 2009, 17(10):458-466.

8. Shenroy AR, Visweswariah SS: Class III nucleotide cyclases in bacteria and archaebacteria: lineage-specific expansion of adenylyl cyclases and a dearth of guanylyl cyclases. FEBS Lett 2004, 561(1-3):11-21.

9. Kimura $Y$, Mishima $Y$, Nakano $H$, Takegawa $K$ : An adenylyl cyclase, CyaA, of Myxococcus xanthus functions in signal transduction during osmotic stress. J Bacteriol 2002, 184(13):3578-3585

10. Kimura Y, Ohtani M, Takegawa K: An adenylyl cyclase, CyaB, acts as an osmosensor in Myxococcus xanthus. J Bacteriol 2005, 187(10):3593-3598.

11. Agarwal N, Lamichhane G, Gupta R, Nolan S, Bishai WR: Cyclic AMP intoxication of macrophages by a Mycobacterium tuberculosis adenylate cyclase. Nature 2009, 460(7251):98-102

12. Agarwal N, Bishai WR: cAMP signaling in Mycobacterium tuberculosis. Indian J Exp Biol 2009, 47(6):393-400.

13. Topal H, Fulcher NB, Bitterman J, Salazar E, Buck J, Levin LR, Cann MJ, Wolfgang MC, Steegborn C: Crystal structure and regulation mechanisms of the CyaB adenylyl cyclase from the human pathogen Pseudomonas aeruginosa. J Mol Biol 2012, 416(2):271-286.

14. Hall RA, De Sordi L, Maccallum DM, Topal H, Eaton R, Bloor JW, Robinson GK, Levin $L R$, Buck J, Wang Y, et al: $C O(2)$ acts as a signalling molecule in populations of the fungal pathogen Candida albicans. PLoS Pathog 2010, 6(11):e1001193.

15. $\mathrm{Xu} \mathrm{XL}$, Lee RT, Fang HM, Wang YM, Li R, Zou H, Zhu Y, Wang Y: Bacterial peptidoglycan triggers Candida albicans hyphal growth by directly activating the adenylyl cyclase Cyr1p. Cell Host Microbe 2008, 4(1):28-39. 
16. Capela D, Barloy-Hubler F, Gouzy J, Bothe G, Ampe F, Batut J, Boistard P, Becker A, Boutry M, Cadieu E, et al: Analysis of the chromosome sequence of the legume symbiont Sinorhizobium meliloti strain 1021. Proc Natl Acad Sci USA 2001, 98(17):9877-9882.

17. Richter W: 3',5' Cyclic nucleotide phosphodiesterases class III: members, structure, and catalytic mechanism. Proteins 2002, 46(3):278-286.

18. Shenoy AR, Visweswariah SS: New messages from old messengers: CAMP and mycobacteria. Trends Microbiol 2006, 14(12):543-550.

19. Jackson EK: The 2',3'-cAMP-adenosine pathway. Am J Physiol Renal Physiol 2011, 301(6):F1160-F1167.

20. Shenoy AR, Sreenath N, Podobnik M, Kovacevic M, Visweswariah SS: The Rv0805 gene from Mycobacterium tuberculosis encodes a 3',5'-cyclic nucleotide phosphodiesterase: biochemical and mutational analysis. Biochemistry 2005, 44(48):15695-15704.

21. Macfadyen LP, Ma C, Redfield RJ: A 3',5' cyclic AMP (cAMP) phosphodiesterase modulates CAMP levels and optimizes competence in Haemophilus influenzae Rd. J Bacteriol 1998, 180(17):4401-4405.

22. Imamura R, Yamanaka K, Ogura T, Hiraga S, Fujita N, Ishihama A, Niki H: Identification of the cpdA gene encoding cyclic 3',5'-adenosine monophosphate phosphodiesterase in Escherichia coli. J Biol Chem 1996, 271(41):25423-25429.

23. Chenna R, Sugawara H, Koike T, Lopez R, Gibson TJ, Higgins DG, Thompson JD: Multiple sequence alignment with the Clustal series of programs. Nucleic Acids Res 2003, 31(13):3497-3500.

24. Podobnik M, Tyagi R, Matange N, Dermol U, Gupta AK, Mattoo R, Seshadri K, Visweswariah SS: A mycobacterial cyclic AMP phosphodiesterase that moonlights as a modifier of cell wall permeability. J Biol Chem 2009, 284(47):32846-32857.

25. Marx CJ, Lidstrom ME: Broad-host-range cre-lox system for antibiotic marker recycling in gram-negative bacteria. Biotechniques 2002, 33(5):1062-1067.

26. Trülzsch K, Roggenkamp A, Pelludat C, Rakin A, Jacobi C, Heesemann J: Cloning and characterization of the gene encoding periplasmic 2', $3^{\prime}$-cyclic phosphodiesterase of Yersinia enterocolitica 0:8. Microbiology 2001, 147(Pt 1):203-213.

27. Sallet E, Roux B, Sauviac L, Jardinaud MF, Carrère S, Faraut T, De Carvalho-Niebel F, Gouzy J, Gamas P, Capela D, et al: Next-generation annotation of prokaryotic genomes with EuGene-P: application to Sinorhizobium meliloti 2011. DNA Res 2013, 20(4):339-354

28. Lawson CL, Swigon D, Murakami KS, Darst SA, Berman HM, Ebright RH: Catabolite activator protein: DNA binding and transcription activation. Curr Opin Struct Biol 2004, 14(1):10-20.

29. Fuchs EL, Brutinel ED, Klem ER, Fehr AR, Yahr TL, Wolfgang MC: In vitro and in vivo characterization of the Pseudomonas aeruginosa cyclic AMP (cAMP) phosphodiesterase $\mathrm{CpdA}$, required for CAMP homeostasis and virulence factor regulation. J Bacteriol 2010, 192(11):2779-2790.

30. Liu J, Burns DM, Beacham IR: Isolation and sequence analysis of the gene (cpdB) encoding periplasmic 2',3'-cyclic phosphodiesterase. J Bacteriol 1986, 165(3):1002-1010.

31. Keppetipola N, Shuman S: A phosphate-binding histidine of binuclear metallophosphodiesterase enzymes is a determinant of 2',3'-cyclic nucleotide phosphodiesterase activity. J Biol Chem 2008, 283(45):30942-30949.

32. Kimura Y, Okazaki N, Takegawa K: Enzymatic characteristics of two novel Myxococcus xanthus enzymes, PdeA and PdeB, displaying 3',5'- and 2',3'-cAMP phosphodiesterase, and phosphatase activities. FEBS Lett 2009, 583(2):443-448.

33. Galperin MY, Bairoch A, Koonin EV: A superfamily of metalloenzymes unifies phosphopentomutase and cofactor-independent phosphoglycerate mutase with alkaline phosphatases and sulfatases. Protein Sci 1998, 7(8):1829-1835.

34. Botha FC, Dennis DT: Isozymes of phosphoglyceromutase from the developing endosperm of Ricinus communis: isolation and kinetic properties. Arch Biochem Biophys 1986, 245(1):96-103.

35. Yakunin AF, Proudfoot M, Kuznetsova E, Savchenko A, Brown G, Arrowsmith $\mathrm{CH}$, Edwards AM: The HD domain of the Escherichia coli tRNA nucleotidyltransferase has 2',3'-cyclic phosphodiesterase, 2'-nucleotidase, and phosphatase activities. J Biol Chem 2004, 279(35):36819-36827.

36. Hantke K, Winkler K, Schultz JE: Escherichia coli exports cyclic AMP via TolC. J Bacteriol 2011, 193(5):1086-1089.

37. Jackson EK, Ren J, Mi Z: Extracellular 2',3'-cAMP is a source of adenosine. $\mathrm{J}$ Biol Chem 2009, 284(48):33097-33106.
38. Vallenet D, Belda E, Calteau A, Cruveiller S, Engelen S, Lajus A, Le Fèvre F, Longin C, Mornico D, Roche D, et al: MicroScope-an integrated microbial resource for the curation and comparative analysis of genomic and metabolic data. Nucleic Acids Res 2013, 41(Database issue):D636-D647.

39. Capela D, Filipe C, Bobik C, Batut J, Bruand C: Sinorhizobium meliloti differentiation during symbiosis with alfalfa: a transcriptomic dissection. Mol Plant Microbe Interact 2006, 19(4):363-372.

40. Arcus VL, McKenzie JL, Robson J, Cook GM: The PIN-domain ribonucleases and the prokaryotic VapBC toxin-antitoxin array. Protein Eng Des Sel 2011, 24(1-2):33-40.

41. Min AB, Miallau L, Sawaya MR, Habel J, Cascio D, Eisenberg D: The crystal structure of the Rv0301-Rv0300 VapBC-3 toxin-antitoxin complex from M. tuberculosis reveals a $\mathrm{Mg}^{2+}$ ion in the active site and a putative RNA-binding site. Protein Sci 2012, 21(11):1754-1767.

42. Jung $K$, Fried $L$, Behr $S$, Heermann R: Histidine kinases and response regulators in networks. Curr Opin Microbiol 2012, 15(2):118-124.

43. Pesavento $C$, Hengge R: Bacterial nucleotide-based second messengers. Curr Opin Microbiol 2009, 12(2):170-176.

44. Corrigan RM, Gründling A: Cyclic di-AMP: another second messenger enters the fray. Nat Rev Microbiol 2013, 11(8):513-524.

45. Becker A, Bergès $H$, Krol E, Bruand C, Rüberg $S$, Capela D, Lauber E, Meilhoc E, Ampe F, De Bruijn FJ, et al: Global changes in gene expression in Sinorhizobium meliloti 1021 under microoxic and symbiotic conditions. Mol Plant Microbe Interact 2004, 17(3):292-303.

46. Pandey SP, Minesinger BK, Kumar J, Walker GC: A highly conserved protein of unknown function in Sinorhizobium meliloti affects sRNA regulation similar to Hfq. Nucleic Acids Res 2011, 39(11):4691-4708.

47. Miller JH: Molecular genetics experiments. Cold Spring Harbor, N.Y: Cold Spring Harbor Laboratory; 1972

doi:10.1186/1471-2180-13-268

Cite this article as: Mathieu-Demazière et al:: Biochemical and functional characterization of SpdA, a 2', 3'cyclic nucleotide phosphodiesterase from Sinorhizobium meliloti. BMC Microbiology 2013 13:268.

\section{Submit your next manuscript to BioMed Central and take full advantage of:}

- Convenient online submission

- Thorough peer review

- No space constraints or color figure charges

- Immediate publication on acceptance

- Inclusion in PubMed, CAS, Scopus and Google Scholar

- Research which is freely available for redistribution

Submit your manuscript at www.biomedcentral.com/submit
C) Biomed Central 